\title{
Zoneamento urbano e direito fundamental ao trabalho: possibilidades para 0 desenvolvimento sustentável
}

\author{
Guilherme Bezerra Barbosa ${ }^{1}$, Felipe Augusto Damaceno de Oliveira ${ }^{2}$ e \\ Pedro Roney Dias Ribeiro ${ }^{3}$
}

\author{
1 Graduando em Direito pela Universidade Federal do Ceará (UFC) \\ 2 Graduando em de Direito pela Universidade de Brasília (UnB) \\ 3 Graduado em Direito pela Universidade Federal do Ceará (UFC). E-mail: pedroroney@hotmail.com
}

\begin{abstract}
RESUM 0: Os problemas relacionados ao direito à moradia se comunicam com outras áreas jurídicas, como o direito ao trabalho digno. Diante disso, objetivou-se verificar os possíveis impactos da política urbana nos direitos do trabaIhador. Portanto, é feita neste estudo uma explanação sobre alguns instrumentos de política urbana e seu possível diálogo com questões relacionadas ao direito do trabalho. Após isso, é feita a exposição da situação de quatro comunidades de Fortaleza. Consegue-se verificar os impactos da política urbana sobre 0 direito ao trabalho digno, sobretudo em relação ao descanso e deslocamento, e, partindo dessas observações, é possível formular algumas considerações.
\end{abstract}

Palavras-chave: Direito urbanístico; sustentabilidade; meio ambiente do trabalho; mobilidade urbana; ZEIS.

\begin{abstract}
The problems related to the right to housing communicate with other legal areas, such as the right to decent work. Therefore, this study aims to verify the possible impacts of urban policy on worker's rights. Thus, an explanation of some urban policy instruments and their possible relation with issues related to worker's rights is made. Following this explanation, the situation of four communities of Fortaleza is analysed. It is possible to verify the impact of urban policy on the right to decent work, notably in the time of rest and in urban mobility. In this way, some considerations are made.

Keywords: Urban-planning law; sustainability; environment of work ${ }^{1}$; Urban mobility; ZEIS.
\end{abstract}

Sumário: 1. Introdução - 2. A Cidade e o trabalho - 3. Estudo de caso - 4. ZEIS - 5. Considerações finais - Referências.

\section{INTRODUÇÃO}

Vive-se em uma época de acelerado crescimento da população urbana e a questão da moradia é um ponto sensível, que deve ser tratado com especial atenção. Esse tema também merece destaque pela sua repercussão em outros interesses da sociedade. 0 direito, aqui en-

\footnotetext{
${ }^{1}$ A expressão "environment of work" parece captar mais satisfatoriamente o significado de "meio ambiente do trabalho" do que a expressão "working environment".
}

Planeta Amazônia: Revista Internacional de Direito Ambiental e Políticas Públicas 
tendido como ordenamento jurídico, é uno, apesar de didaticamente dividido em diversos ramos, e como tal deve ser interpretado em sua unidade. Assim, é possível que os problemas relacionados ao direito à moradia (direito urbanístico) se comuniquem com outras áreas jurídicas, como o direito ao meio ambiente ecologicamente equilibrado (direito ambiental) e 0 direito ao trabalho digno (direito do trabalho).

Partindo dessa premissa, pretende-se com o presente estudo verificar os possíveis impactos da política urbana e do planejamento de uso e ocupação do solo nas questões trabaIhistas, marcadamente na garantia dos direitos do cidadão trabalhador. Para tanto, realiza-se uma explanação teórica, explicando alguns instrumentos de política urbana e suas consequências práticas na vida dos obreiros residentes nos locais de implementação dessa política. Após isso, será exposto o estudo de caso realizado em quatro comunidades de Fortaleza (Serviluz, Raízes da Praia, Campo do América e Santa Cecília), na tentativa de identificar as diferenças entre as políticas implementadas em cada uma delas e como tais diferenças influenciaram na melhoria ou na degradação do meio ambiente de trabalho dos moradores. As duas primeiras comunidades estão localizados em zona litorânea e em proximidade do ecossistema de mangue, o que lhes dá contornos peculiares, com maior homogeneidade de ocupações laborais, normalmente relacionadas à pesca ou ao turismo. As duas últimas são comunidades de ocupação histórica, encrustadas em áreas nobres da cidade, com intensa atividade comercial e grande fluxo de pessoas, o que faz com que o local seja alvo de intensa especulação imobiliária.

Importa salientar que a opção pela metodologia baseada em estudos de casos se deu por dois motivos principais. Primeiramente porque traz um aspecto prático do direito, revelando se as teorias desenvolvidas guardam, de fato, relação com a realidade dos trabalhadores. Além disso, o estudo de caso permite que as conclusões relativas a comunidades específicas possam indicar os prováveis resultados que seriam obtidos em comunidades com características semelhantes, através da adoção da mesma política. Em outras palavras, esse método, apesar de focado em determinada comunidade, possibilita a expansão de suas conclusões, com dados relativos à efetividade das políticas públicas.

Dito isso, passa-se à exposição da base teórica, que auxiliará na compreensão da realidade verificada no estudo de caso.

\section{A CIDADE E 0 TRABALHO}

Ainda no século XX, a população urbana, no Brasil, superou a população rural. De acordo com o censo de 2010 do Instituto Brasileiro de Geografia e Estatística (IBGE), a população urbana brasileira constitui $84,35 \%$ da população total do país (IBGE, 2010). De fato, o mundo segue tendência semelhante de urbanismo acelerado, como observa M ike Davis:

Com efeito, as cidades absorveram quase dois terços da explosão populacional global desde 1950 e hoje o crescimento é de 1 milhão de bebês e migrantes por semana. A força de trabalho urbana do mundo mais que dobrou desde 1980 , e a população urbana de 3,2 bilhões de pessoas é maior do que a população total do mundo quando 
John F. Kennedy tomou posse (2006, p.13-14).

Conclui-se a partir disso que as relações sociais humanas perpassam cada vez mais a dinâmica das cidades. 0 ser humano, ao criar e se organizar em cidades, criou para si uma espécie de habitat, um mundo no qual a própria dinâmica da organização e uso do espaço gera impactos imediatos na vida dos indivíduos. A questão urbana, portanto, perpassa e é perpassada por outros aspectos da sociedade humana, em um movimento dialético e indissociável (HARVEY, 2014).

A crescente importância das cidades para a vida humana estimulou, cada vez mais, a produção de normas que versassem sobre o tecido urbano, com o objetivo de pensar funções e objetivos para a cidade. Entende-se, portanto, definições de cidade como a presente em Henri Lefebvre, que afirma que "a cidade é a projeção da sociedade sobre um local" (2011, p. 56). Desde, pelo menos, 1933, com a Carta de Atenas, afirma-se que a cidade encerra algumas funções elementares, quais sejam: habitar, recrear, circular e trabalhar. Assim, observa-se que havia certa preocupação em relacionar as funções da cidade com a garantia do direito ao trabalho já na primeira metade do século XX.

Por mais que a relação entre a produção do espaço urbano e os demais aspectos da sociedade humana já fosse bem conhecida e teorizada, a matriz do planejamento urbano brasileiro, durante todo o século XX, manteve-se norteada por paradigmas técnicos e positivistas (FONTES, 2010). Foi durante a Ditadura Militar que tal modelo de planejamento urbano atingiu o seu ápice. 0 intuito de se planejar as cidades, de acordo com o modelo modernista/funcionalista típico desse momento histórico brasileiro, era, sobretudo, mitigar o caos urbano, fruto da histórica ocupação desordenada do solo presente nas cidades brasileiras (FONTES, 2010). Tal modelo de desenvolvimento urbano, contudo, não logrou o êxito pretendido em combater a ocupação desordenada do solo, nem promoveu o correto desenvolvimento das funções da cidade, uma vez que, pensado de forma tecnicista e autoritária, não foi capaz de lançar as condições jurídicas necessárias para um modelo de planejamento urbano mais abrangente, aberto ao diálogo em relação às necessidades específicas de cada local das cidades.

A ordem jurídico estatal inaugurada pela Constituição Federal de 1988 (CF/88), embora esteja longe de abranger a totalidade das contradições apresentadas pelas cidades brasileiras, permitiu o desenvolvimento do conceito de direito à cidade, pois estabeleceu as bases para um direito urbanístico calcado em princípios como a participação popular obrigatória (CARMONA, 2015). Com efeito, o caput do art. 182, presente no capítulo da política urbana da $\mathrm{CF} / 88$, determina que "a política de desenvolvimento urbano, executada pelo Poder Público municipal, conforme diretrizes gerais fixadas em lei, tem por objetivo ordenar o pleno desenvolvimento das funções sociais da cidade e garantir o bem-estar de seus habitantes" (BRASIL, 1988).

O referido dispositivo, na linha da nova hermenêutica constitucional, deve ser interpretado de forma teleológico sistemática, em conjunto com os princípios constitucionais, bem como outras normas presentes na CF/88 tais como as referentes ao trabalho, ao meio ambi- 
ente e à política urbana. Portanto, o que foi disposto no art. 225, que trata do meio ambiente, deve ser aplicado na elaboração e interpretação de normas do direito urbanístico. Dentre as espécies de meio ambiente, cabe aqui destacar o meio ambiente do trabalho, que é mencionado no art. 200, inciso VIII, da CF/ 88.

Observa-se, então, que o direito constitucional à cidade é um conceito amplo, que abrange os mais variados aspectos da vida humana. Através da articulação e interpretação dos elementos acima expostos, é possível afirmar que a garantia de um meio ambiente do trabaIho equilibrado é pressuposto do direito à cidade e, conforme o estabelecido no art. 182, os municípios, ao elaborarem as diretrizes básicas da política urbana de determinada localidade, possuem papel importante na concretização de tal direito presente na Constituição.

Nesse sentido, a Lei no 10.257/2001, o Estatuto da Cidade, estabeleceu os paradigmas nacionais para aplicação da política urbana constitucional. Assim, no art. $2^{\circ}$, está estabelecida a base para o conceito legal de direito à cidade:

Art. $2^{-}$A política urbana tem por objetivo ordenar o pleno desenvolvimento das funções sociais da cidade e da propriedade urbana, mediante as seguintes diretrizes gerais: I - garantia do direito a cidades sustentáveis, entendido como o direito à terra urbana, à moradia, ao saneamento ambiental, à infra-estrutura urbana, ao transporte e aos serviços públicos, ao trabalho e ao lazer, para as presentes e futuras gerações (BRASIL, 2001).

Ressalte-se que a garantia ao trabalho digno deve ser levada em conta na elaboração dos planos diretores dos municípios com mais de 20 mil habitantes. A partir daí, é possível concluir que a questão do uso e ocupação do solo urbano mantém relação com o direito do trabalho.

Paulo Afonso Cavichioli Carmona (2015) fornece alguns exemplos dessa relação. No tocante à questão do deslocamento, a relação entre o direito do trabalho e o direito urbanístico é imediata. Para o desenvolvimento de uma cidade, é imprescindível a implementação de uma política de mobilidade urbana que garanta o direito de ir e vir do trabalhador até o seu local de trabalho, bem como a diminuição ao máximo do ônus relacionado ao transporte, 0 que implica na formulação de um modelo de mobilidade urbana sustentável e eficiente. Nesse espeque, pode-se destacar 0 art. $7^{\circ}$ da Lei $n-12.587 / 2012$, que instituiu as diretrizes da Política Nacional de M obilidade Urbana:

Art. $7^{0}$ A Política Nacional de Mobilidade Urbana possui os seguintes objetivos:

I - reduzir as desigualdades e promover a inclusão social; II - promover o acesso aos serviços básicos e equipamentos sociais; III - proporcionar melhoria nas condições urbanas da população no que se refere à acessibilidade e à mobilidade; IV - promover o desenvolvimento sustentável com a mitigação dos custos ambientais e socioeconômicos dos deslocamentos de pessoas e cargas nas cidades; e $\mathrm{V}$ - consolidar a gestão democrática como instrumento e garantia da construção contínua do aprimoramento da mobilidade urbana. (BRASIL, 2012). 
Dessa forma, conclui-se que é importante prover os meios para uma política urbana sustentável que garanta o direito de ir e vir do trabalhador. Entretanto, tal política deve ser aliada a um planejamento do uso do solo urbano, uma vez que a distância entre o local de trabalho e o local de repouso do trabalhador podem acarretar em um dispêndio demasiado excessivo de tempo relacionado ao transporte, tempo este que poderia servir de descanso e recuperação do trabalhador.

A ocupação desordenada do solo pode gerar outras consequências relevantes para a relação entre direito urbanístico e direito do trabalho, além da distância entre local de trabaIho e local de descanso e lazer do trabalhador. De fato, a falta de planejamento pode acarretar em situações em que o meio ambiente do trabalho seja desrespeitado diretamente. Como observa Carmona (2015), "Efetivamente, é difícil de imaginar a convivência harmônica entre uma barulhenta ferraria e um prédio de escritórios, disputando o mesmo espaço na urbe, 0 que demonstra a importância que o zoneamento desenvolverá nesse tema".

Tendo em vista que a importância, para o direito do trabalho, do zoneamento urbano e das diversas formas de planejamento e ocupação do solo não se esgotam nas duas hipóteses acima apresentadas, torna-se importante 0 desenvolvimento de breves considerações acerca de tais instrumentos de planejamento urbano.

José Afonso da Silva, tratando da natureza e objetivos do zoneamento urbano, afirma que

O zoneamento constitui, pois, um procedimento urbanístico que tem por objetivo regular o uso da propriedade do solo e dos edifícios em áreas homogêneas, no interesse do bem-estar da população. Ele serve para encontrar lugar para todos os usos essenciais do solo e dos edifícios na comunidade e colocar cada coisa em seu lugar adequado, inclusive as atividades incômodas (2010, p.238).

As diversas funções da cidade, incluindo a função do trabalho, portanto, precisam ser pensadas conjuntamente com a questão do uso do solo. Embora o urbanismo moderno tenha procurado afastar a noção de zoneamento exclusivo, ou seja, a prática urbanística de delimitar certas partes da cidade a uma só atividade ou função, costuma-se falar de zoneamento que estabeleça zonas de uso predominante.

Com efeito, parece ser mais eficiente e mais coerente com realidade fática e jurídica das cidades brasileiras, procurar estabelecer zonas de uso predominante, no lugar de zonas de uso exclusivo. A grande maioria das cidades brasileiras cresceu e se desenvolveu de maneira desordenada, por meio de ocupações, o que já colocaria dificuldades imensas para formas de zoneamento de zonas exclusivas, uma vez que toda a construção histórica do uso desordenado do solo provavelmente inviabilizaria qualquer tentativa unilateral de homogeneização de determinada área da cidade.

Há mais pontos a serem abordados sobre os problemas que o zoneamento de zonas de uso exclusivo poderia acarretar, todavia tal não é o foco do presente estudo. Cabe ressaltar ainda que o zoneamento de uso predominante é instrumento interessante para o planejamento do uso do solo urbano, pois pode ser adequado às realidades da cidade, ao mesmo 
tempo que pode apontar para parâmetros e objetivos a serem alcançados, visando à construção de uma cidade sustentável.

Adotando tais paradigmas para o zoneamento urbano, é possível, pelo menos em teoria, pensar a ocupação do solo das cidades de maneira que as diversas funções e atividades do espaço urbano coexistam de maneira integrada e racional. Seria possível, por exemplo, conciliar atividades turísticas, na orla de cidades litorâneas, com atividades portuárias, garantindo ainda o direito ao meio ambiente natural sustentável para a população em geral e o direito ao meio ambiente do trabalho para aqueles que vivem de atividades pesqueiras, turísticas e semelhantes.

Na prática, o que se observa é que os interesses privados se sobressaem aos interesses públicos. Destarte, as cidades são regidas predominantemente pela especulação imobiliária e não pelos paradigmas estabelecidos pelos instrumentos de planejamento urbano. É notável a capacidade que grupos econômicos dominantes possuem de sequestrar parcelas do estado, exercendo grande influência sobre a implementação de políticas públicas e sobre a aplicação das normas urbanísticas.

Desta forma, a máquina pública do município muitas vezes acaba colaborando com a concretização desses interesses privados, no lugar de trabalhar para coibir os efeitos negativos da especulação imobiliária. Geralmente, os mais afetados por essa dinâmica fazem parte da população economicamente mais frágil, pois as intervenções sobre a cidade, muitas vezes debatidas de maneira superficial com a coletividade, podem gerar mudanças expressivas na sua dinâmica de vida, produzindo também consequências jurídicas interessantes ao direito do trabalho.

\section{ESTUDO DE CASO}

Optou-se por analisar o zoneamento territorial no município de Fortaleza, a partir da ótica do direito ao trabalho digno, contrastando uma ocupação urbana desordenada com atividades artesanais e tradicionais de trabalho como a pesca. Analisa-se principalmente esta atividade, mas não só.

Quinta cidade mais populosa e a mais densamente povoada do país, Fortaleza possui 24 quilômetros de orla. A faixa de praia representa uma pequena parcela de seu território, mas é seu principal cartão postal e chamariz para turistas. De frente para o mar mora também o punhado mais rico de sua população, que encontrou na avenida Beira Mar seu alojamento privilegiado. No entanto, grande parte da extensão da orla leste e oeste da cidade foi ao longo do século XX ocupada por comunidades de pescadores ou de migrantes vindos do interior, não raro impelidos pelos efeitos das periódicas estiagens no Sertão. Estas comunidades permanecem até hoje nessas áreas (...) (Documentário Areia Loteada, 2015).

Este é o texto de apresentação do Documentário Areia Loteada. 0 filme tem por objetivo retratar como os interesses imobiliários e o Projeto Aldeia da Praia, da Prefeitura de Fortaleza, pretendem remover diversas comunidades da região da Praia do Futuro, litoral leste da

Planeta Amazônia: Revista Internacional de Direito Ambiental e Políticas Públicas 
cidade.

Conforme informado pelos moradores, o Serviluz, bairro afetado pelo projeto, é ocupado há mais de 40 anos e atualmente possui cerca de 4 mil famílias, sendo a atividade pesqueira fator de geração de renda importante para muitas delas. Para concretizar um projeto de reurbanização com uma praça e aparelhos de lazer, a Prefeitura pretende remover essas famílias para uma área que fica a três quilômetros do local atual.

Importante analisar o prejuízo trazido aos pescadores, uma vez que com a distância sua atividade ficará prejudicada. M orando à beira da praia os trabalhadores guardam seus barcos na frente de suas casas, realizam a manutenção destes ali mesmo no "quintal de casa". Os peixes pescados são guardados em suas próprias geladeiras, para consumo próprio, ou depois de congelados são vendidos em mercados da região. Destacam-se os problemas decorrentes da mobilidade destes pescadores, pois o percurso a ser realizado é em meio a área urbana, por ruas e avenidas extremamente movimentadas, não tendo sequer transporte público que atenda a essa demanda, em virtude da relativa curta distância.

Em outra perspectiva, a Comunidade Raízes da Praia é fruto de uma ocupação que já dura mais de 5 anos (período necessário para se pleitear, via ação de usucapião, a propriedade de um imóvel urbano ocupado pacificamente) em um terreno que estava vazio há 25 anos, com famílias advindas de outras desocupações promovidas pela Prefeitura de Fortaleza. Após inúmeras tentativas de reintegração de posse, a comunidade segue resistindo. Dado o tempo da ocupação, os moradores despenderam esforços em construir suas casas (uma grande parte em alvenaria) e ali se instalar. Nesse contexto, devido à proximidade em relação ao polo turístico e comercial da Praia do Futuro, para além dos pescadores que ali vivem, encontra-se outra questão ligada ao trabalho: as barracas de praia.

Por estar localizada próxima à praia, a comunidade acaba por fornecer mão de obra para as barracas de praia que ali existem, com o intuito de atender aos frequentadores. Desse modo qualquer desocupação destes moradores dificultaria ou impossibilitaria a continuidade das suas atividades de trabalho, uma vez que esta população seria deslocada para regiões do interior da cidade muito distantes deste local de trabalho. Tal fato evidencia como o direito à moradia tem intima relação com a garantia de permanência e acesso ao direito ao trabalho.

No mesmo sentido, quando se olha para o interior, para dentro da cidade de Fortaleza, encontram-se situações explícitas de descaso em relação a um planejamento sustentável e humano do espaço urbano, por parte do poder público. Tomando como exemplo a Aldeota e o M eireles, dois bairros contíguos possuindo o metro quadrado mais caro da cidade, vemos o contraste dos apartamentos e hotéis luxuosos com comunidades de resistência à "invasão" das classes ricas. Esse é o contexto no qual se insere a comunidade do Campo do América e a comunidade Santa Cecília (GARCIA, 2014).

Muito antes dos condomínios fechados, a Aldeota era lar de vilas de pescadores e outras populações que trabalhavam no Porto do Mucuripe, e ali se instalavam pela proximidade em relação a esse equipamento. Assim, há quase 100 anos a Comunidade do Campo do América vive ao redor e nas mediações de um campo de futebol que anteriormente pertencera ao América Futebol Clube, contando atualmente com cerca de 4 mil famílias (GARCIA, 2014). 
Com a transformação da região em área nobre, as tentativas de desocupação dos moradores foram inúmeras. 0 que no início era um bairro de trabalhadores que ficava próximo ao mar, com a modificação da cidade passou a ser uma região próxima dos mais variados serviços, de lazer, educação, cultura e saúde, além da grande proximidade com os novos postos de trabalho da população.

Dessa forma, percebe-se que a luta desses moradores não é só por seu direito de ali continuar, em resistência, mas se deu em grande parte pelo direito ao trabalho que essa parte da população de Fortaleza possui. Importante trazer que em qualquer local que a Prefeitura decidisse realocar essa comunidade, tomando-se por base os atuais locais de reassentamento, o povo gastaria de uma hora e meia a duas horas de deslocamento aos antigos locais de trabalho. Tal fato demonstra não só a importância da resistência, mas também que a dinâmica da cidade deve ser entendida no intuito de aproximação da moradia ao posto de trabalho.

Em relação à comunidade Santa Cecília, observa-se um tipo diferente de abordagem. Tendo a mesma lógica de formação e ocupação apresentada, a comunidade exerceu sua resistência através de um programa do Governo do Ceará, em meados dos anos 70, quando o Governador Virgílio Távora lançou o Programa de Assistência às Favelas da Região M etropolitana, no qual optou-se pela padronização e regularização das casas da área, e a posterior concessão dos títulos de propriedade, sem a necessidade de remoção para áreas afastadas da cidade. Isso permitiu que as famílias permanecessem próximas às suas atividades de trabalho e lazer sem que para isso gastassem metade do seu dia no deslocamento, dentro de ônibus, no trânsito caótico da cidade.

\section{ZEIS}

Contemporaneamente, visando à promoção da regularização fundiária de interesse social, ou seja, uma política de urbanismo que minimize as remoções e garanta o direito à cidade e ao trabalho a comunidades no local onde elas já se encontram assentadas, o direito urbanístico brasileiro acolheu 0 instituto das Zonas Especiais de Interesse Social (ZEIS).

A lei federal 11977/2009, no seu artigo 47, V, conceitua Zona Especial de Interesse Social como "parcela de área urbana instituída pelo Plano Diretor ou definida por outra lei municipal, destinada predominantemente à moradia de população de baixa renda e sujeita a regras específicas de parcelamento, uso e ocupação do solo" (BRASIL, 2009).

No caso de Fortaleza, o Plano Diretor é a lei municipal que estabelece as diretrizes da política urbana a serem adotadas. 0 Plano Diretor Participativo de Fortaleza, de 2009, demarcou 135 ZEIS, sendo estas divididas

em 45 ZEIS do Tipo 1 (compostas de assentamentos com ocupação desordenada, em áreas públicas ou particulares, constituídos por população de baixa renda, precários do ponto de vista urbanístico e habitacional); 56 ZEIS do Tipo 2 (compostas por loteamentos clandestinos ou irregulares e conjuntos habitacionais, ocupados por população de baixa renda) e; 34 ZEIS do Tipo 3 (compostas de áreas dotadas de infraestrutura, com concentração de terrenos não edificados ou imóveis subutilizados ou não uti-

Planeta Amazônia: Revista Internacional de Direito Ambiental e Políticas Públicas 
lizados, devendo ser destinados à implementação de empreendimentos habitacionais de interesse social) (FORTALEZA)

Embora 0 instituto de que se trata tenha demonstrado resultados positivos em cidades como Recife, em Fortaleza trata-se apenas de previsão, uma vez que nenhuma das 135 ZEIS foram regulamentadas até a presente data.

O potencial de aplicar índices especiais a certas áreas demarcadas como ZEIS, de forma integrada com o zoneamento urbano de Fortaleza, com o intuito de garantir a permanência e a garantia do direito à cidade a comunidades em situação de fragilidade econômica é só um dos exemplos das possibilidades oferecidas pelos instrumentos já previstos no ordenamento jurídico brasileiro.

Todavia, a exemplo das ZEIS, vários desses institutos estão previstos na legislação federal, mas não são regulamentados pela legislação municipal ou, mesmo quando regulamentados, são aplicados (muitas vezes subaplicados), de forma isolada, sem uma visão estratégica e orgânica da cidade, de modo que casos de violações de direitos como aqueles aqui brevemente relatados se mostram recorrentes.

A regulamentação e a criação de novas ZEIS poderiam trazer a segurança jurídica que acompanha a regularização fundiária, ao mesmo tempo que garantiriam a permanência da população beneficiada nos lugares historicamente ocupados e construídos por esta. Nessa perspectiva, problemas como a inviabilização da garantia ao meio ambiente do trabalho para os cidadãos que habitam em áreas de ZEIS do tipo 1, por exemplo, poderiam ser reduzidos.

\section{CONSIDERAÇÕES FINAIS}

Pelo exposto, consegue-se verificar os impactos da política urbana sobre o direito ao trabalho digno, marcadamente na equação entre o tempo de descanso e deslocamento e na própria possibilidade de exercício da atividade remunerada não eventual.

Com efeito, as remoções planejadas pelo poder público distanciam os trabalhadores do seu local de labor, reduzindo assim seu tempo de descanso, que é utilizado para execução do itinerário. Como é cediço, a falta de descanso reflete negativamente na saúde e na segurança do trabalho, aumentando os índices de doenças laborais (inclusive de caráter psíquico) e de acidentes de trabalho.

Além disso, 0 afastamento de sua moradia habitual pode inviabilizar a permanência do cidadão na condição de trabalhador. Isso porque, para o pescador, por exemplo, a distância do mar é fator essencial na viabilidade e no lucro auferido pela atividade. Assim, caso haja aumento nessa distância, pode o cidadão se ver em situação em que os gastos não compensem o esforço de trabalho e não gerem a renda mínima para a sobrevivência digna.

Em comparação entre as comunidades estudadas, percebemos as vantagens da política de regularização fundiária, com a manutenção das pessoas em sua morada habitual, na vida do cidadão trabalhador. Tais medidas favorecem a permanência dos moradores no mercado de trabalho e possibilitam a manutenção de uma dignidade mínima nas atividades laborais.

Por último, argumentou-se brevemente, utilizando-se ilustrativamente do instituto ju- 
rídico e urbanístico ZEIS, que o direito brasileiro já conta, na sua legislação, com o aporte necessário para dar resposta a muitos problemas presentes na cidade de Fortaleza, sobretudo quando se fala na violação do direito ao trabalho, resultante da falta de planejamento urbano adequado.

Portanto, além do uso antidemocrático das prerrogativas da administração pública, pode-se atribuir também parcela das consequências do desenvolvimento desorganizado e desestruturado da cidade de Fortaleza à falta de regulamentação e aplicação dos instrumentos de política urbana, previstos na legislação brasileira.

\section{REFERÊNCIAS}

BRASIL. Constituição da República Federativa do Brasil de 1988. Brasília: Presidência da República, 1988. Disponível em: বhttp://www.planalto.gov.br/ccivil_03/constituicao/constituica o.htm>. Acesso em: dez. 2015.

BRASIL. Lei $\mathbf{n}^{\circ}$ 10257. Brasília: Presidência da República, 2001. Disponível em: বttp://www. planalto.gov.br/ccivil_03/leis/LEIS_2001/L10257.htm>. Acesso em: dez. 2015.

BRASIL. Lei $\mathbf{n}^{\circ}$ 11977. Brasília: Prēesidência da República, 2009. Disponível em: বhttp://www. planalto.gov.br/ccivil_03/_ato2007-2010/2009/lei//11977.htm>

BRASIL. Lei $\mathbf{n}^{\circ}$ 12587. Brasília: Presidência da República, 2012. Disponível em: বttp://www. planalto.gov.br/ccivil_03/_ato2011-2014/2012/lei/l12587.htm>. Acesso em: dez. 2015.

CARM ONA, Paulo Afonso Cavichioli. Curso de direito urbanístico. Bahia: Juspodivm, 2015.

FONTES, Mariana Levy Piza. Planejamento urbano e o marco jurídico-urbanístico no Brasil. Revista Magister de Direito Ambiental e Urbanístico, Porto Alegre, v. 5, n. 27, p. 45-55, dez./jan. 2010.

FORTALEZA. Instituto de Planejamento de Fortaleza. Zonas especiais de interesse social. Disponível em: 〈http:// www.fortaleza.ce.gov.br/iplanfor/zonas-especiais-de-interesse-social> HARVEY, David. Cidades Rebeldes: do direito à cidade à revolução urbana. São Paulo: Martins Fontes, 2014.

LEFEBVRE, Henri. 0 direito à cidade. São Paulo: Centauro, 2011.

SILVA, José Afonso da. Direito urbanístico brasileiro. 6. ed. São Paulo: M alheiros, 2010.

AREIA Loteada, Nigéria Filmes. Direção: Nigéria Filmes. Diretor de Fotografia: Bruno Xavier, Roger Pires e Yargo Gurgel. Fortaleza, 2015.

GARCIA, Fátima. Aldeota Pobre. Fortaleza, 2014. Disponível em: «tttp://www.fortalezaem fotos.com.br/2014/07/a-aldeota-pobre.html>. Acesso em: dez. 2015.

Artigo recebido em 26 de agosto de 2016.

Aprovado em 31 de dezembro de 2016. 